Article

\title{
Synthesis of Valeric Acid by Selective Electrocatalytic Hydrogenation of Biomass-Derived Levulinic Acid
}

\author{
Yan Du, Xiao Chen *®D, Ji Qi ${ }^{\circ}$, Pan Wang and Changhai Liang * \\ State Key Laboratory of Fine Chemicals, Laboratory of Advanced Materials and Catalytic Engineering, \\ School of Chemical Engineering, Dalian University of Technology, Dalian 116024, China; \\ sunshine233@mail.dlut.edu.cn (Y.D.); jiqi@dlut.edu.cn (J.Q.); panwang92@outlook.com (P.W.) \\ * Correspondence: xiaochen@dlut.edu.cn (X.C.); changhai@dlut.edu.cn (C.L.)
}

Received: 19 May 2020; Accepted: 17 June 2020; Published: 19 June 2020

\begin{abstract}
The electrocatalytic hydrogenation (ECH) of biomass-derived levulinic acid (LA) is a promising strategy to synthetize fine chemicals under ambient conditions by replacing the thermocatalytic hydrogenation at high temperature and high pressure. Herein, various metallic electrodes were investigated in the ECH of LA in a H-type divided cell. The effects of potential, electrolyte concentration, reactant concentration, and temperature on catalytic performance and Faradaic efficiency were systematically explored. The high conversion of LA (93\%) and excellent "apparent" selectivity to valeric acid (VA) (94\%) with a Faradaic efficiency of $46 \%$ can be achieved over a metallic lead electrode in $0.5 \mathrm{M} \mathrm{H}_{2} \mathrm{SO}_{4}$ electrolyte containing $0.2 \mathrm{M} \mathrm{LA}$ at an applied voltage of $-1.8 \mathrm{~V}$ (vs. $\mathrm{Ag} / \mathrm{AgCl})$ for $4 \mathrm{~h}$. The combination of adsorbed LA and adsorbed hydrogen $\left(\mathrm{H}_{\mathrm{ads}}\right)$ on the surface of the metallic lead electrode is key to the formation of VA. Interestingly, the reaction performance did not change significantly after eight cycles, while the surface of the metallic lead cathode became rough, which may expose more active sites for the ECH of LA to VA. However, there was some degree of corrosion for the metallic lead cathode in this strong acid environment. Therefore, it is necessary to improve the leaching-resistance of the cathode for the ECH of LA in future research.
\end{abstract}

Keywords: electrocatalytic hydrogenation; levulinic acid; valeric acid; lead

\section{Introduction}

Biomass energy, derived directly or indirectly from the photosynthesis of green plants, is a unique renewable carbon source. The development of biomass energy is of great significance for the synthesis of fine chemicals and recycling clean fuels [1-3]. The U.S. Energy Agency has selected the 12 most representative platform compounds based on more than 300 biomass-derived compounds, in which levulinic acid (LA) can be easily and economically produced from lignocellulosic materials through a simple hydrolysis process [4]. The hydrogenation of LA can (in)directly generate $\gamma$-valerolactone (GVL), valeric acid (VA), dimethyltetrahydrofuran, and 1,4-pentanediol. Among them, VA derived from the complete hydrogenation of the carbonyl group of LA can be utilized to prepare flavors, refrigerants, synthesis valerates, n-octane, valeric anhydride, and other downstream products [5]. GVL can be used in the production of lubricants, plasticizers, flavors, and solvents for insoluble resins. Therefore, the development of a transformation method of LA with high efficiency, good selectivity to high-value target products, and lower energy consumption in mild conditions is highly desirable and concurrently has an immense research worth.

Traditionally, the catalytic transformation of LA is operated through thermocatalytic hydrogenation (TCH) at high temperature and high pressure in a batch reactor using $\mathrm{H}_{2}$ gas or organic solvents as the hydrogen source. Aiming at the hydrogenation of LA to VA, Li et al. reported that $97 \%$ yields of 
VA and valerate esters could be achieved over a Co/HZSM- 5 catalyst at $3 \mathrm{MPa}$ and $240{ }^{\circ} \mathrm{C}$ for $3 \mathrm{~h}[6]$. Using Ru/HZSM- 5 as a heterogeneous catalyst, Weckhuysen et al. directly converted LA to VA with a yield of $45.8 \%$ in dioxane as the solvent at $200{ }^{\circ} \mathrm{C}$ for $4 \mathrm{~h} \mathrm{[7].} \mathrm{Recently,} \mathrm{several} \mathrm{research} \mathrm{groups} \mathrm{have}$ demonstrated that the catalytic transfer hydrogenation is a promising method for the conversion of LA and its esters to GVL using several bio-alcohols or formic acid in the liquid/gas phase because it does not require the use of high pressure $\mathrm{H}_{2}$ [8-11]. However, the stability of the catalyst should be considered, as it is easy to form substantial coke (catalyst deactivation) in the $\mathrm{TCH}$ process. In addition, the output of high energy is not conducive to sustainable development to some extent [12].

In contrast, electrocatalytic hydrogenation $(\mathrm{ECH})$ operating in relatively mild conditions is a promising approach for the conversion of biomass-derived LA. Using clean and sustainable water as the hydrogen source, the reaction can be performed at atmospheric pressure and room temperature, thus avoiding the explosion of $\mathrm{TCH}$ and the overuse of expensive organic compounds hydrogen sources [13]. The selectivity to the target products can be controlled by adjusting the cell potential/current density, temperature, electrolyte $\mathrm{pH}$, and so on [14]. Another attractive feature is that the electrical energy required for the reaction can be obtained from renewable energy, such as wind and solar $[15,16]$. By comparison, the thermal energy for TCH is mostly from fossil fuel resources, including coal, oil, and natural gas, which are adverse to sustainable development to a certain extent.

As can be shown from the above, the entire process of ECH is more environmental-friendly, has great research value and application prospects, and is becoming the focus of current research [12,17-20]. However, due to the competition of water splitting to generate $\mathrm{H}_{2}$, the $\mathrm{ECH}$ of biomass conversion in aqueous solution always results in low conversion and Faradaic efficiency (FE), which means that the electron transfer is not fully used for hydrogenation of substrates but for producing $\mathrm{H}_{2}$ and other byproducts. In general, the hydrogen evolution reaction (HER) mainly competes with ECH, and it is thus necessary to find a way to suppress HER or achieve high conversion and good selectivity. When it comes to the ECH of LA, Schröder first proposed a two-step electrochemical conversion of LA to octane via VA over $\mathrm{Pb}$ and Pt electrodes, and clarified the application of electrochemistry in the production of renewable chemicals and biofuels [21]. Subsequently, it was found that the composition of the electrolyte, the reactant concentration, and the nature of the electrode material had a strong influence on the selectivity of product formation [22]. Xin et al. conducted the ECH of LA in a single-poly-mer electrolyte membrane electrocatalytic (flow) cell reactor and found that the conversion of LA at $-1.5 \mathrm{~V}$ vs. reversible hydrogen electrode (RHE) could reach $96.8 \%$ over a Pb electrode for $10 \mathrm{~h}$ through a four-electron transfer [23]. Furthermore, the addition of formic acid could increase the conversion of LA to some extent [24]. Recently, Wu reported that GVL was the only product and the FE could reach $78.6 \%$ in the ECH of LA when using PbS with different degrees of oxidation as a catalyst and 1-butyl-3-methylimidazolium tetrafluoroborate as the electrolyte [25]. However, some reaction parameters that are all important aspects of the direct conversion of LA to VA over the ECH process have not been investigated in depth. The reaction mechanism and the stability of electrodes in the acid environment also need to be examined.

Herein, the ECH of biomass-derived LA was systematically investigated in an H-type cell separated by a Nafion membrane using water as the source of hydrogen. The effects of cathode materials, potential, electrolyte concentration, reactant concentration, and temperature on the catalytic performance and FE were systematically explored. The ECH mechanism of LA to VA over metallic $\mathrm{Pb}$ as a cathode was confirmed. In addition, the stability of the cathode material was evaluated. This work not only contributes knowledge about the reaction system for the ECH of LA from the perspective of stability and reactivity, but also provides a meaningful guidance for the design of efficient metal electrocatalysts for large-scale biomass upgrading applications. 


\section{Results}

\subsection{ECH of LA in H-Type Cell}

Generally, mutual competition and dependence relations coexist between the ECH of LA and $\mathrm{H}_{2}$ evolution, which are greatly dependent on the nature of cathode materials and the choice of reduction potentials. As shown in Figure 1, various metals ( $\mathrm{Pb}, \mathrm{Zn}, \mathrm{Ti}, \mathrm{Co}, \mathrm{Pt}$, and $\mathrm{Cu}$ ) as cathodes were investigated. Under the same reaction conditions, for instance, $0.2 \mathrm{M}$ sulfuric acid as the electrolyte containing $0.2 \mathrm{M} \mathrm{LA},-1.8 \mathrm{~V}$, and reaction time $2 \mathrm{~h}$, metallic $\mathrm{Pb}$ stands out clearly over the other materials $(\mathrm{Zn}, \mathrm{Ti}, \mathrm{Co}, \mathrm{Pt}$, and $\mathrm{Cu}$ ) in terms of LA conversion to $\mathrm{VA}$, with the conversion of LA reaching $56 \%$ and the selectivity to VA achieving 95\% with 77\% FE of VA. Although metallic Zn has the highest selectivity to VA (ca. 99\%), the FE of VA (ca. 20\%) is much lower than that of $\mathrm{Pb}$. According to the Tafel formula $\left(\eta=a+b \lg i\right.$, where $\eta$ is the overpotential $(\mathrm{V}), i$ is the current density $\left(\mathrm{A} / \mathrm{m}^{2}\right)$, and $a$ and $b$ are Tafel constants), the pure metal electrode has a fixed hydrogen evolution constant under acidic/basic conditions. It should be remarked that the best candidates for ECH may not be the metals with high overpotential for the HER, since adsorbed hydrogen is needed for the hydrogenation reaction as well. Because metallic Pt with low overpotential has an excellent ability to produce adsorbed hydrogen, it is used for the electrocatalytic reaction of phenol and furfural at a lower current potential or current density $[26,27]$. However, there is no denying that the ability of Pt to produce hydrogen at high potential is significantly stronger than that of ECH. Therefore, both conversion and FE are very low at $-1.8 \mathrm{~V}$. Surprisingly, metallic $\mathrm{Cu}$ with medium overpotential seems unfriendly to the ECH of LA (the conversion of LA is only $10 \%$ ), even though $\mathrm{Cu}$ foam, a porous material with 3D structure, provides low resistance diffusion channels, promoting diffusion and ion transport of the electrolyte. In previous research, $\mathrm{Cu}$-based catalysts presented outstanding performances in the ECH of furfural and 5-hydroxymethylfufural $[19,28,29]$. It can be seen that the affinity of different organic molecules on the same metal surface is different, which largely determines the ECH activity, rather than the overpotential for $\mathrm{H}_{2}$. By comparison, the excellent ability of $\mathrm{Pb}$ to adsorb $\mathrm{LA}$ may promote the electron and electrolyte ion transfer efficiently, enhancing the activation of carbonyl in LA. Consequently, with the aim of achieving a highly efficient conversion of LA to VA through ECH over a metallic Pb electrode, the critical parameters were systematically explored.

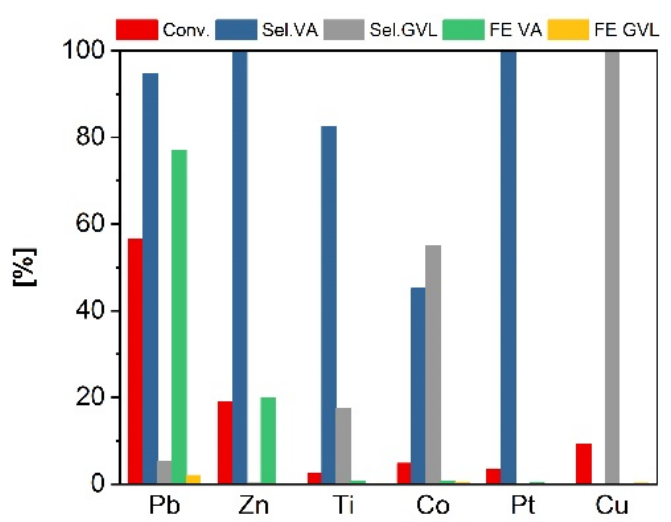

Figure 1. Conversion of levulinic acid (LA), selectivity to products, and Faradaic efficiency (FE) for the electrocatalytic hydrogenation (ECH) of LA to valeric acid (VA) and $\gamma$-valerolactone (GVL) at various types of metallic electrodes. Conditions: $0.2 \mathrm{M} \mathrm{LA}, 0.2 \mathrm{M} \mathrm{H}_{2} \mathrm{SO}_{4}$ electrolyte, $-1.8 \mathrm{~V} \mathrm{vs}$. Ag/AgCl, $2 \mathrm{~h}$.

The effect of the applied potential on the catalytic hydrogenation performance of LA was investigated at $4 \mathrm{~h}$ in $50 \mathrm{~mL}$ of $0.5 \mathrm{M}$ sulfuric acid with $0.2 \mathrm{M}$ LA. Figure 2 shows that the polarization extent of the metallic $\mathrm{Pb}$ electrode can be controlled by changing the applied potential, thus governing the products distribution, which is similar to previously reported results [23]. At $-1.4 \mathrm{~V}, 84 \%$ selectivity to VA with a FE of $56 \%$ is observed for a LA conversion of $17 \%$. At $-1.6 \mathrm{~V}$, the selectivity to VA increases to $92 \%$ ( $8 \%$ to GVL), and the LA conversion and FE to VA increase to $65 \%$ and $71 \%$, respectively. 
When the applied potential drops to $-1.8 \mathrm{~V}$, the selectivity to VA increases to $94 \%$, LA conversion jumps to $93 \%$, but FE decrases to $46 \%$. When the potential further decreases to $-2.0 \mathrm{~V}$, the VA selectivity as well as LA conversion increase slightly, while the FE of VA dramatically decreases to $25 \%$. The results demonstrate that the negative potential not only will enhance the conversion of LA but also is conducive to the formation of VA, which can be attributed to the fact that the ECH of LA involves a serial four-electron pathway through the intermediate 4-hydroxyvaleric acid [30]. The reaction intermediate can be further hydrogenated to VA or desorbed into the bulk electrolyte to form GVL. However, the FE to VA decreases significantly with the decrease in applied potential, which can be attributed to the enhancement of $\mathrm{H}_{2}$ evolution at more negative potential. Therefore, the ECH of LA and the $\mathrm{H}_{2}$ evolution should be balanced by tuning the applied voltage so that enough adsorbed hydrogen $\left(\mathrm{H}_{\mathrm{ads}}\right)$ generated in situ on the electrode is present to drive the hydrogenation of carbonyl in LA.

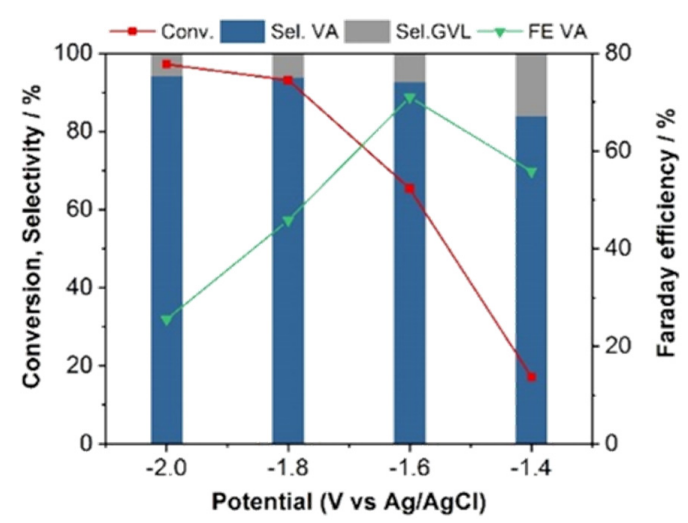

Figure 2. Conversion of LA, selectivity to VA and GVL, and FE (related to VA) versus different potentials. Conditions: $\mathrm{Pb}$ cathode, $0.2 \mathrm{M} \mathrm{LA}, 0.5 \mathrm{M} \mathrm{H}_{2} \mathrm{SO}_{4}$ and $4 \mathrm{~h}$.

In order to understand the ECH path of LA, as shown in Figure 3, the conversion of LA as well as the yield of VA and GVL versus reaction time were examined. As the reaction time increases, the concentration of the reactant (LA) drops, and the yield of products (VA and GVL) increases. Unfortunately, carbon loss (ca. 8-18\%) is observed, which may be attributed that some by-products, such as pinacol, angelica lactone, or condensate are not detected by HPLC. Furthermore, the consumption rate of the substrate gradually slows down with increasing electrolytic time, and the FE shows a downward trend as a whole, e.g., the FE of VA drops from $72 \%$ to $46 \%$ over $4 \mathrm{~h}$. This can be because the concentration of LA on the surface of the working electrode decreases evidently. Under such circumstances, it is easier for the hydrion in the solution and the adsorbed hydrogen on the electrode surface to combine with each other, causing the $\mathrm{H}_{2}$ evolution profits to happen.

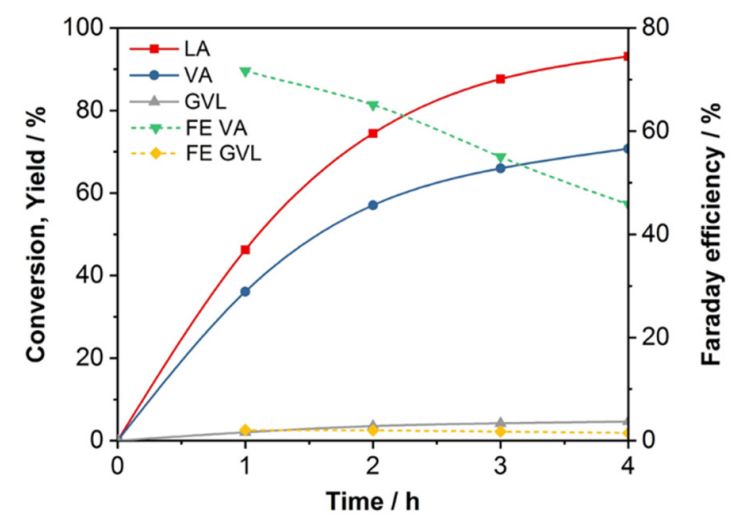

Figure 3. Conversion, yield, and $\mathrm{FE}$ of products versus the reaction time. Conditions: $\mathrm{Pb}$ cathode, $0.2 \mathrm{M} \mathrm{LA}, 0.5 \mathrm{M} \mathrm{H}_{2} \mathrm{SO}_{4}$ electrolyte, and $-1.8 \mathrm{~V}$ vs. $\mathrm{Ag} / \mathrm{AgCl}$. 
The concentration of hydrion is of vital importance in the ECH of LA. Figure 4 presents the effect of concentrations of the sulfuric acid electrolyte at the potential of $-1.8 \mathrm{~V}$ for $1 \mathrm{~h}$. The conversion of LA obviously improves with decreasing $\mathrm{pH}$ of the solution. When the concentration of sulfuric acid changes from $0.25 \mathrm{M}$ to $1.0 \mathrm{M}$, the conversion of LA has almost doubled, which is attributed to the enhancement of electrolytic ability of water and the boost of hydrion generation. However, the FE of VA decreases slightly at lower $\mathrm{pH}$. In essence, taking acid electrolyte as an example, the Volmer step (Equation (1)), in which $\mathrm{H}^{+}$gets electrons on the cathode surface to form the adsorbed hydrogen $\left(\mathrm{H}_{\mathrm{ads}}\right)$, provides subsequent $\mathrm{ECH}$ steps with $\mathrm{H}_{\mathrm{ads}}$ as the hydrogen source. However, this $\mathrm{H}_{\mathrm{ads}}$ also participates in the Tafel (Equation (2)) and Heyrovsky (Equation (3)) steps.

$$
\begin{gathered}
\text { Volmer step : } \mathrm{H}^{+}+\mathrm{e}^{-} \rightarrow \mathrm{H}_{\mathrm{ads}} \\
\text { Tafel step : } 2 \mathrm{H}_{\mathrm{ads}} \rightarrow \mathrm{H}_{2} \\
\text { Heyrovsky step : } \mathrm{H}_{\mathrm{ads}}+\mathrm{H}^{+}+\mathrm{e}^{-} \rightarrow \mathrm{H}_{2}
\end{gathered}
$$

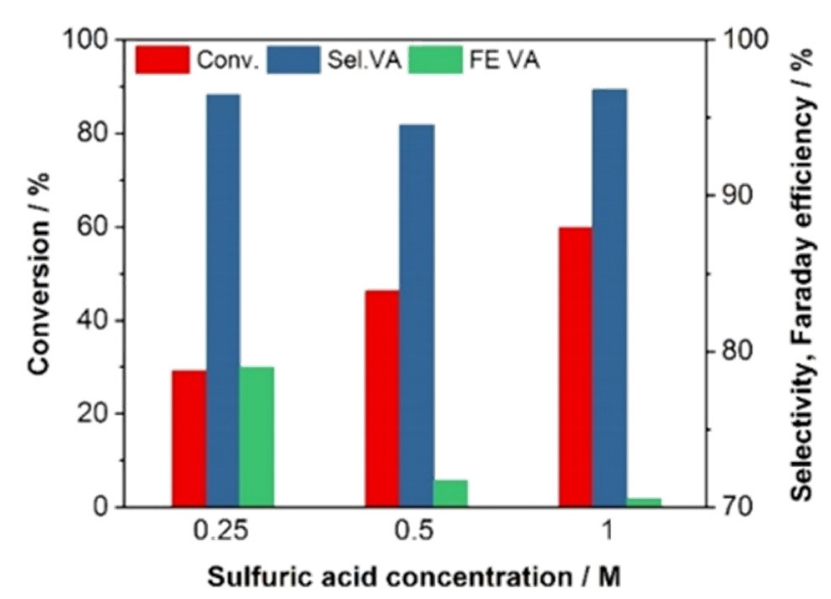

Figure 4. Conversion of LA, selectivity to VA, and FE of VA at different sulfuric acid concentrations as the electrolyte. Conditions: $\mathrm{Pb}$ cathode, $0.2 \mathrm{M} \mathrm{LA},-1.8 \mathrm{~V}$ vs. $\mathrm{Ag} / \mathrm{AgCl}$, and $1 \mathrm{~h}$.

At high hydrion concentration, more $\mathrm{H}_{\text {ads }}$ generated on the surface of the $\mathrm{Pb}$ electrode has the opportunity to combine with $\mathrm{H}^{+}$to form $\mathrm{H}_{2}$, which is an unwanted side reaction that reduces the density of $\mathrm{H}_{\mathrm{ads}}$ and consumes the applied electricity. In addition, the adsorption of LA on the catalyst site of the working electrode is also a key step for the $\mathrm{ECH}$. The solution $\mathrm{pH}$ may affect the ionization state of LA, potentially changing its adsorption characteristics, which will influence the products distribution.

The unique catalytic ability of metallic $\mathrm{Pb}$ for the ECH of LA to VA was examined by comparing its linear sweep voltammograms (LSV). As shown in Figure 5a, the cathodic current density obtained without LA is due to the $\mathrm{H}_{2}$ evolution. However, when LA is present, the onset potential for the reduction current density moves to the positive direction and reaches $-1.22 \mathrm{~V}$, suggesting that the ECH of LA is superior to the $\mathrm{H}_{2}$ evolution over the metallic $\mathrm{Pb}$ electrode. This further confirms that the metallic $\mathrm{Pb}$ is a promising electrode for directional transformation of LA by electrocatalysis. Comparing the LSV curves of different starting reactant concentrations, there is no dramatic change in the current density, probably because of the limitation of electrode surface adsorption sites. However, when the starting reactant concentration is down to $0.1 \mathrm{M}$, the unwanted hydrogen evolution is more competitive with the ECH of LA, resulting in a low FE of VA (as shown in Figure $5 b$ ).

With increasing concentration of LA from $0.1 \mathrm{M}$ to $0.5 \mathrm{M}$, the generated $\mathrm{H}_{\text {ads }}$ via hydrion on the surface of the working electrode is easier to combine with organic molecules during the $\mathrm{ECH}$ process, leading the FE of VA to an upward trend from $51 \%$ to $72 \%$. In addition, the selectivity to VA shows almost no change, staying at ca. $95 \%$. However, the conversion of LA shows an obvious downward 
trend from $59 \%$ to $20 \%$. This may be due to the close contact between the active surface of the $\mathrm{Pb}$ electrode and the aqueous solution, which cannot provide sufficient reaction sites to withstand the higher concentration of LA hydrogenation. Overall, for sustaining the high conversion of LA and high FE of VA, the optimal LA concentration is $0.2 \mathrm{M}$ over a metallic $\mathrm{Pb}$ electrode.
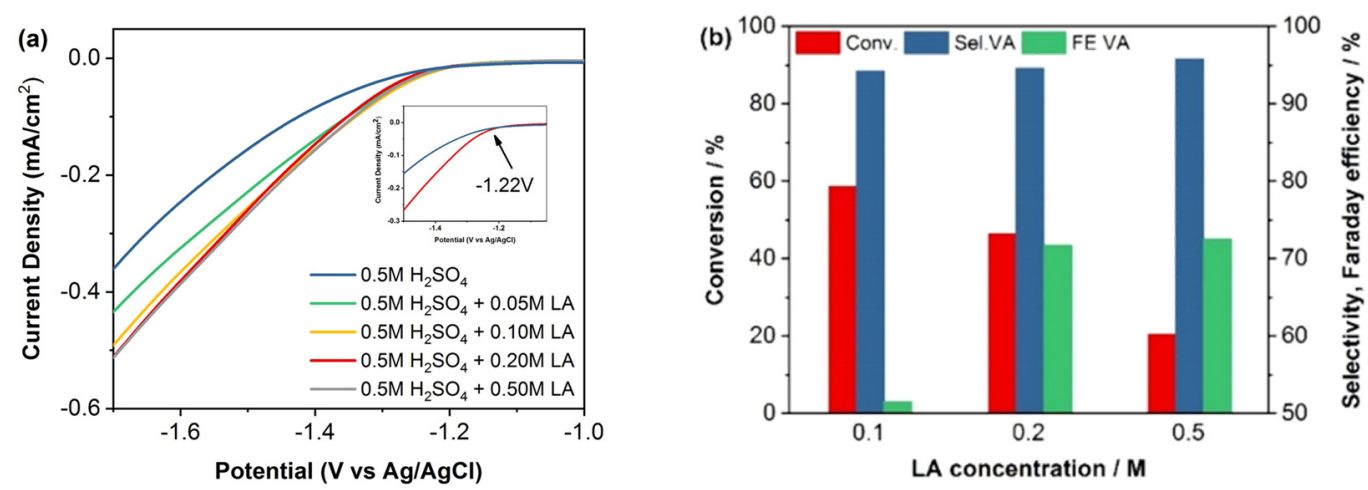

Figure 5. (a) Linear sweep voltammetry (LSV) curves with the different LA concentrations in $0.5 \mathrm{M}$ $\mathrm{H}_{2} \mathrm{SO}_{4}$ as catholyte, and (b) conversion of LA, selectivity to VA, and FE of VA at different LA concentrations over $\mathrm{Pb}$ cathode at $-1.8 \mathrm{~V}$ vs. $\mathrm{Ag} / \mathrm{AgCl}$ for $1 \mathrm{~h}$.

In the traditional TCH of LA, the equilibrium moves to the direction of the endothermic reaction when the temperature rises. The same phenomenon is found in the ECH of LA [27]. As shown in Table 1, the effect of the temperature was studied with $0.5 \mathrm{M}$ sulfuric acid as catholyte at $-1.8 \mathrm{~V}$ for $1 \mathrm{~h}$. When the reaction temperature rises from $25^{\circ} \mathrm{C}$ to $80^{\circ} \mathrm{C}$, the overall conversion increases from $46 \%$ to $68 \%$, and the ECH rate shows an upward tendency (from $14 \mathrm{mmol} \mathrm{L}^{-1} \mathrm{~min}^{-1}$ to $23 \mathrm{mmol} \mathrm{L}^{-1} \mathrm{~min}^{-1}$ ). The high experimental temperature accelerates the movement of hydrion from the anode to the cathode, while the LA molecules involved in the reaction get more energy, which promotes the hydrogenation of LA on the surface of the metallic Pb electrode. A similar temperature effect on the conversion of feedstock and the FE of the target product has been previously reported in the $\mathrm{ECH}$ of furfural to furfuryl alcohol over a $3 \% \mathrm{Pt} / \mathrm{ACF}$ electrode using $0.1 \mathrm{M} \mathrm{H}_{2} \mathrm{SO}_{4}$ as catholyte at the potential of $-0.5 \mathrm{~V}$ [27]. It should be noted that the $\mathrm{H}_{2}$ evolution is also enhanced under the high reaction temperature $\left(80^{\circ} \mathrm{C}\right)$, which leads to the FE of VA $(59 \%)$ being lower than that at low temperature $(74 \%$ at $65{ }^{\circ} \mathrm{C}$ ) due to the competition between $\mathrm{ECH}$ and hydrogen desorption. In addition, the selectivity to VA was also influenced by the reaction temperature due to the side reaction, e.g., the formation of GVL. Therefore, taking into account the energy consumption and the catalytic conversion efficiency, the ECH of LA to VA is preferably conducted at $65^{\circ} \mathrm{C}$ over a metallic Pb cathode in $0.2 \mathrm{M} \mathrm{LA}$ in $0.5 \mathrm{M}$ $\mathrm{H}_{2} \mathrm{SO}_{4}$ at $-1.8 \mathrm{~V}$ for $4 \mathrm{~h}$.

Table 1. ECH of LA with different temperatures over $\mathrm{Pb}$ cathode in $0.2 \mathrm{M} \mathrm{LA}$ in $0.5 \mathrm{M} \mathrm{H}_{2} \mathrm{SO}_{4}$ at $-1.8 \mathrm{~V}$ vs. $\mathrm{Ag} / \mathrm{AgCl}$ for $1 \mathrm{~h}$.

\begin{tabular}{|c|c|c|c|c|}
\hline Temperature $\left[{ }^{\circ} \mathrm{C}\right]$ & Conversion $[\%]$ & Selectivity VA [\%] & Faradaic Efficiency VA [\%] & $\begin{array}{l}\text { Electrocatalytic Hydrogenation } \\
\text { Rate }\left[\mathrm{mmol} \mathrm{L}^{-1} \mathrm{~min}^{-1}\right]\end{array}$ \\
\hline 25 & 46 & 94 & 72 & 14 \\
\hline 50 & 56 & 97 & 72 & 18 \\
\hline 65 & 66 & 96 & 74 & 21 \\
\hline 80 & 68 & 91 & 59 & 23 \\
\hline
\end{tabular}

\subsection{Reaction Process and Mechanism}

According to the above systematic investigation and the previous literature [23], the reaction process and mechanism of ECH of LA to 4-hydroxyvaleric acid, VA, and GVL was further summarized and consummated (as shown in Figure 6). It must be emphasized that the affinity of organic molecules for the surface of the metallic $\mathrm{Pb}$ electrode largely determines the ECH activity [31]. In acidic electrolytes, 
the adsorbed LA is activated by the $\mathrm{H}_{\mathrm{ads}}$ on the metallic lead surface and is then hydrogenated into the intermediate of 4-hydroxyvaleric acid. Most of 4-hydroxyvaleric acid continues to adsorb on the electrode surface to produce $\mathrm{VA}$, which then desorbs from the surface of metallic $\mathrm{Pb}$. A small portion of the 4-hydroxyvaleric acid intermediate desorbs from the surface of the electrode and dehydrates to generate GVL. In addition, the effect of the temperature on the ECH of LA can be well explained using this principle. Both the ECH of LA and HER are electron-getting processes as well as exothermic processes. Compared with the $\mathrm{H}_{2}$ evolution, the ECH of LA to VA dominates at relatively low temperatures, which inhibits the desorption of hydrogen and enhances the combination of $\mathrm{H}_{\text {ads }}$ with the unstable 4-hydroxyvaleric acid intermediate to form VA.

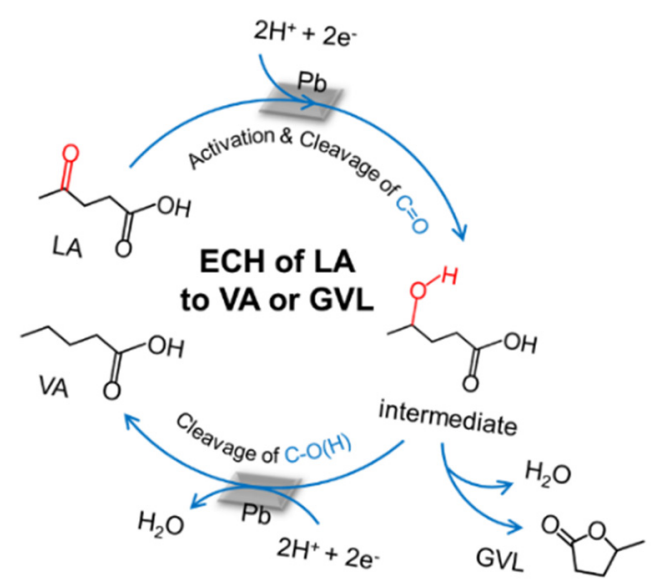

Figure 6. Specific reaction pathway combined with adsorption for the ECH of LA to form 4-hydroxyvaleric acid, VA, and GVL.

\subsection{Stability Testing}

Catalyst lifetime is a key consideration in the economical production of VA from bio-derived $\mathrm{LA}$. Therefore, the stability of the metallic $\mathrm{Pb}$ electrode during the $\mathrm{ECH}$ of LA was further examined according to the determined reaction conditions with $0.5 \mathrm{M}$ sulfuric acid containing $0.2 \mathrm{M}$ LA as catholyte and $0.5 \mathrm{M}$ sulfuric acid as anolyte at $-1.8 \mathrm{~V}$ under room temperature for $4 \mathrm{~h}$. After each cycle, the Pb electrode was cleaned with DI water and ethanol, and then used in the next reaction. Figure 7 reveals that there is no dramatic change in the conversion of LA (above 90\%), and a very high VA selectivity of ca. $94 \%$ with a FE of ca. $48 \%$ is sustained after 8 cycles. This excellent recycling performance of the ECH of LA to VA over a metallic $\mathrm{Pb}$ electrode has never been reported. However, there is corrosion on the surface of the metallic $\mathrm{Pb}$ electrode in a strong acid environment according to a previously proposed mechanism [32,33]. The results of inductively coupled plasma atomic emission spectroscopy (ICP-AES) show that the content of $\mathrm{Pb}$ in the solution of the first, fourth, and eighth cycle test was $0.5032 \mathrm{mg} / \mathrm{L}, 5.714 \mathrm{mg} / \mathrm{L}$, and $3.255 \mathrm{mg} / \mathrm{L}$, respectively. The effect of metallic $\mathrm{Pb}$ on the structure stability was also determined using SEM images, as shown in Figure 8 . The surface of fresh metallic $\mathrm{Pb}$ is relatively flat with traces of scratches due to the treatment with sand paper (Figure $8 \mathrm{a}, \mathrm{b}$ ). After stability tests, various flakes and rods are formed on the surface of the spent metallic $\mathrm{Pb}$ electrode (Figure 8c,d). In addition, a modification of morphology such as reconstruction may happen on the entire metal surface due to the adsorption of LA. The electrode surface becomes rough, which may expose more active sites for the ECH of LA to VA. However, the corrosion behavior of metallic $\mathrm{Pb}$ in the acid system would lead to the contamination of the products, creating problems for their separation and purification. It is thus necessary to design a highly efficient catalytic material with leaching-resistance for the ECH of LA to VA. 


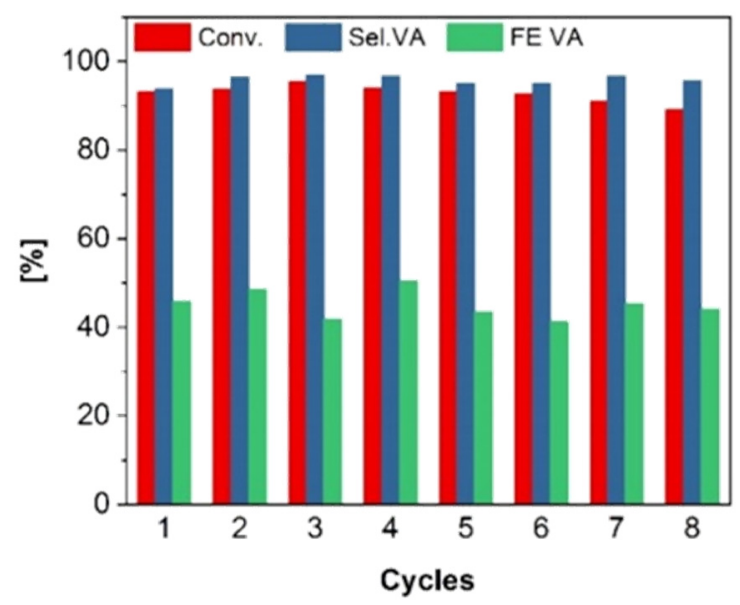

Figure 7. Stability testing of metallic Pb electrode in an H-type cell with $0.2 \mathrm{M} \mathrm{LA}$ as reactant and $0.5 \mathrm{M}$ $\mathrm{H}_{2} \mathrm{SO}_{4}$ as electrolyte at $-1.8 \mathrm{~V}$ vs. $\mathrm{Ag} / \mathrm{AgCl}$ under room temperature for $4 \mathrm{~h}$.

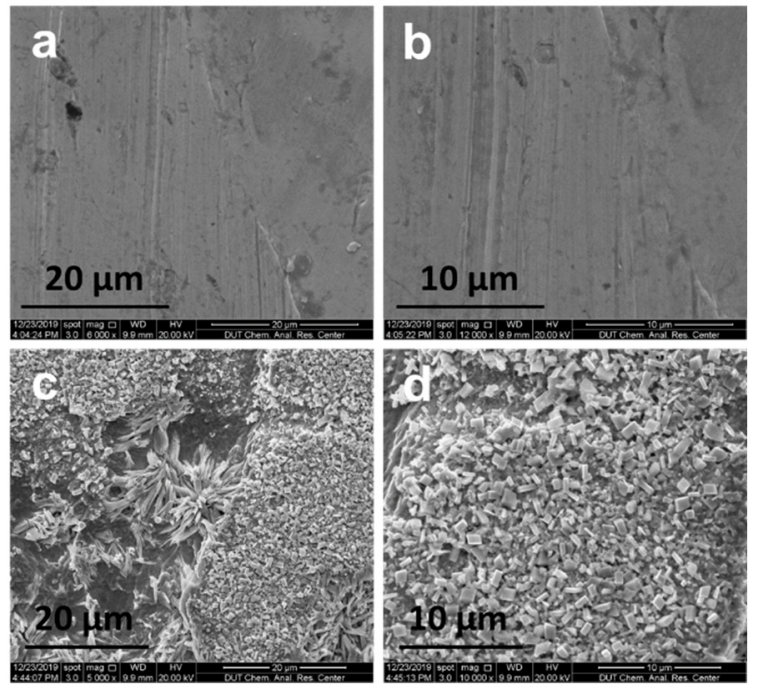

Figure 8. SEM images of $(\mathbf{a}, \mathbf{b})$ fresh and $(\mathbf{c}, \mathbf{d})$ spent metallic $\mathrm{Pb}$ electrode.

\section{Materials and Methods}

\subsection{Chemicals and Materials}

Chemicals of analytical grade were used in all experiments. LA (99.0\%) was purchased from Aladdin Chemical Reagent Co., Ltd., Shanghai, China. The lead (Pb) sheet ( $\geq 99.9 \%)$ was purchased from Jinan Dingsheng Metal Material Co., Ltd., Jinan, China. Zinc (Zn), titanium (Ti), cobalt (Co) sheets ( $\geq 99.9 \%$ ) were purchased from Baoji Tengfeng Metal Materials Co., Ltd., Baoji, China. The platinum $(\mathrm{Pt})$ sheet $(\geq 99.9 \%)$ was purchased from Shanghai Jingchong Electronic Technology Development Co., Ltd., Shanghai, China. Copper (Cu) foam (porosity factor 98\%) was purchased from Kunshan Guangjiayuan New Material Co., Ltd., Kunshan, China. The H-type electrolytic cell was purchased from Shanghai Jingchuang Electronic Technology Development Co., Ltd., Shanghai, China. The Nafion 117 membranes used in the electrochemical device were purchased from DuPont, Wilmington, Delaware, USA. Before the electrochemical measurement, the metal sheet as an electrode was cut into a piece $1 \mathrm{~cm} \times 1.2 \mathrm{~cm}$, then rinsed in $3 \mathrm{M} \mathrm{HCl}$, treated with sand paper (except $\mathrm{Cu}$ foam), and washed with deionized water to remove contaminants from the surface. 


\subsection{Electrochemical Measurements}

All electrochemical measurements were operated on an Autolab PGSTAT302N/FRA workstation equipped with a three-electrode system. The metal sheet after pre-treatment was used as the working electrode. The platinum sheet and $\mathrm{Ag} / \mathrm{AgCl}(0.198 \mathrm{~V}$ vs. standard hydrogen electrode (SHE)) were applied as counter and reference electrodes, respectively. All electrode potentials in this study were reported versus $\mathrm{Ag} / \mathrm{AgCl}$ otherwise specified. Electrochemical measurements were operated in a H-type cell divided by Nafion 117 membranes with $50 \mathrm{~mL}$ anode and cathode chambers (Figure 9). The geometric area of the working electrode was uniformly maintained at $1 \mathrm{~cm}^{2}$. During the whole experiment, the catholyte was purged nitrogen with stirring at atmospheric pressure. To investigate the ECH performance of LA over metal electrodes, linear sweep voltammetry (LSV) curves were tested with a scan rate of $50 \mathrm{mV} \mathrm{s}^{-1}$ in $0.5 \mathrm{M} \mathrm{H}_{2} \mathrm{SO}_{4}$ solution with and without LA. Chronoamperometry experiments were conducted at different applied potentials and other conditions for the organic substrates' electrolysis in the reaction system.
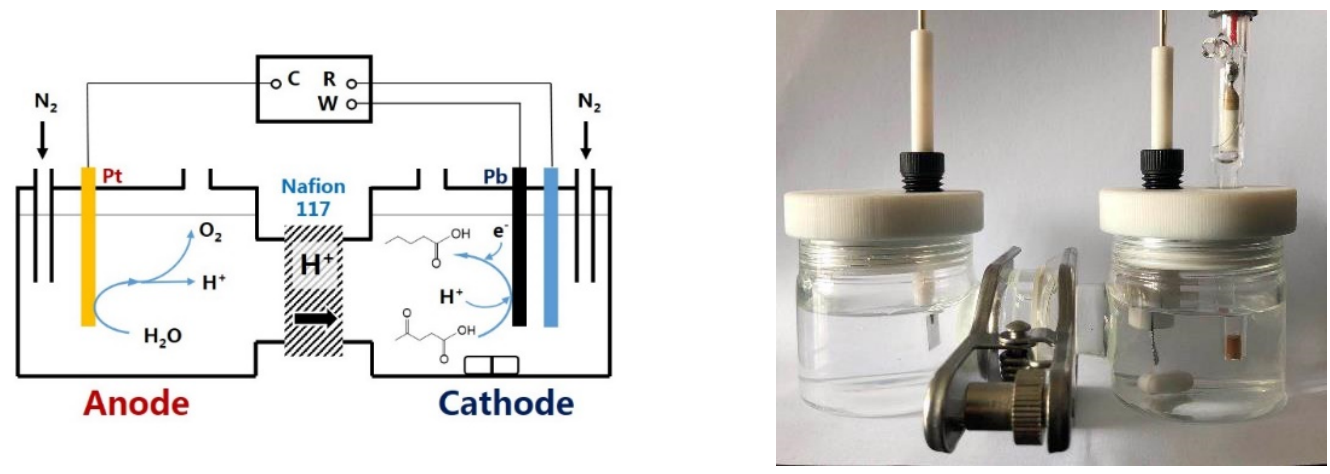

Figure 9. Diagram and actual photo of electrochemical device.

After the testing, the reaction products contained in the cathode electrolyte were qualitatively and quantitatively analysed by HPLC (Waters 1525) with a refractive index detector (Waters 2414). An OA-1000 column (Alltech, Grace) was operated at $85^{\circ} \mathrm{C}$, and $0.045 \mathrm{M} \mathrm{H}_{2} \mathrm{SO}_{4}$ solution was applied as eluent $\left(0.3 \mathrm{~mL} \mathrm{~min}^{-1}\right)$ for product separation. A sample volume of $15 \mu \mathrm{L}$ was injected into the HPLC system. The products were identified by comparison with standard samples. Standard curves were drawn for the quantitative analysis. The conversion of LA, the "apparent" selectivity to products, the yield of products, and FE were calculated using the following equations [23,24]:

$$
\begin{gathered}
\text { Conversion of LA }(\%)=\frac{\text { mol of LA consumed }}{\text { mol of initial LA }} \times 100 \% \\
\text { Selectivity to } X(\%)=\frac{\text { mol of } X \text { formed }}{\text { mol of all identified products }} \times 100 \% \\
\text { FE }(\%)=\frac{\text { mol of } X \text { formed }}{\text { total charge passed }(\mathrm{C}) /(\mathrm{F} \times \mathrm{n})} \times 100 \% \\
\text { Yield of } \mathrm{X}(\%)=\frac{\mathrm{mol} \text { of } \mathrm{X} \text { formed }}{\text { mol of initial LA }} \times 100 \% \\
\text { ECH rate }\left(\mathrm{mmol} \mathrm{L}^{-1} \mathrm{~min}^{-1}\right)=\frac{\text { mmol of LA consumed }}{\text { volume }(\mathrm{L}) \times \text { time }(\mathrm{min})} \times 100 \%
\end{gathered}
$$

where $\mathrm{X}$ is VA or GVL, F is the Faraday constant $\left(96485 \mathrm{C} \mathrm{mol}^{-1}\right)$, and $n$ is the number of electrons required for the conversion of one LA molecule to one corresponding molecule of VA $(n=4)$ or GVL $(n=2)$. 


\subsection{Analysis}

The morphologies of the metal electrodes before and after the reaction were characterized with a scanning electron microscopy (SEM, QUANTA 450, FEI Ltd., USA) instrument. The metal content in the reaction solution after the stability testing was measured by inductively coupled plasma atomic emission spectroscopy (ICP-AES, Optima 2000 DV device, Perkin-Elmer, USA).

\section{Conclusions}

Compared with the traditional TCH of biomass-derived LA, the ECH of LA can be achieved in relatively mild conditions with the utilization of clean and sustainable water as a hydrogen source. Over the metallic Pb electrode, the high conversion of LA (93\%) and excellent "apparent" selectivity to VA $(94 \%)$ with a FE of $46 \%$ can be achieved with $0.5 \mathrm{M} \mathrm{H}_{2} \mathrm{SO}_{4}$ electrolyte and $0.2 \mathrm{M} \mathrm{LA}$ at an applied voltage of $-1.8 \mathrm{~V}$ (vs. $\mathrm{Ag} / \mathrm{AgCl}$ ) for $4 \mathrm{~h}$. In order to balance the $\mathrm{ECH}$ of $\mathrm{LA}$ and the $\mathrm{H}_{2}$ evolution, the adsorption hydrogen $\left(\mathrm{H}_{\mathrm{ads}}\right)$ should be controlled precisely by tuning the cell potential/current density, temperature, and electrolyte $\mathrm{pH}$, inhibiting the Tafel and Heyrovsky steps, and promoting the formation of VA. Interestingly, the reaction performance does not change significantly after eight cycles. The surface of the metallic $\mathrm{Pb}$ cathode becomes rough, which may expose more active sites for the ECH of LA to VA. However, the corrosion behavior of the metallic Pb electrode in the acid system leads to the contamination of the products. It is thus necessary to improve the leaching-resistance of the cathode to achieve the environmentally friendly conversion of biomass in future research.

Author Contributions: The individual contribution of authors to the present work was as follows: conceptualization and data analysis, Y.D. and X.C.; methodology, Y.D. and P.W.; writing — original draft preparation, Y.D.; writing-review and editing, X.C. and J.Q.; resources and supervision, C.L.; funding acquisition, X.C. and C.L. All authors have read and agreed to the published version of the manuscript.

Funding: This work was financially supported by the Natural Science Foundation of China (21573031 and 21703028), and the Science and Technology Innovation Fund in Dalian City (2019J12GX028).

Conflicts of Interest: The authors declare no conflict of interest.

\section{References}

1. Luterbacher, J.S.; Rand, J.M.; Alonso, D.M.; Han, J.; Youngquist, J.T.; Maravelias, C.T.; Pfleger, B.F.; Dumesic, J.A. Nonenzymatic Sugar Production from Biomass Using Biomass-Derived $\gamma$-Valerolactone. Science 2014, 343, 277. [CrossRef]

2. Wang, G.-H.; Hilgert, J.; Richter, F.H.; Wang, F.; Bongard, H.J.; Spliethoff, B.; Weidenthaler, C.; Schüth, F. Platinum-cobalt bimetallic nanoparticles in hollow carbon nanospheres for hydrogenolysis of 5-hydroxymethylfurfural. Nat. Mater. 2014, 13, 293-300. [CrossRef]

3. Lynd, L.R.; Wyman, C.E.; Gerngross, T.U. Biocommodity Engineering. Biotechnol. Progr. 1999, 15, 777-793. [CrossRef] [PubMed]

4. Corma, A.; Iborra, S.; Velty, A. Chemical Routes for the Transformation of Biomass into Chemicals. Chem. Rev. 2007, 107, 2411-2502. [CrossRef] [PubMed]

5. Serrano-Ruiz, J.C.; Dumesic, J.A. Catalytic routes for the conversion of biomass into liquid hydrocarbon transportation fuels. Energy Environ. Sci. 2011, 4, 83-99. [CrossRef]

6. Sun, P.; Gao, G.; Zhao, Z.; Xia, C.; Li, F. Stabilization of Cobalt Catalysts by Embedment for Efficient Production of Valeric Biofuel. ACS Catal. 2014, 4, 4136-4142. [CrossRef]

7. Luo, W.; Deka, U.; Beale, A.M.; van Eck, E.R.H.; Bruijnincx, P.C.A.; Weckhuysen, B.M. Ruthenium-catalyzed hydrogenation of levulinic acid: Influence of the support and solvent on catalyst selectivity and stability. J. Catal. 2013, 301, 175-186. [CrossRef]

8. Kuwahara, Y.; Kaburagi, W.; Osada, Y.; Fujitani, T.; Yamashita, H. Catalytic transfer hydrogenation of biomass-derived levulinic acid and it esters to $\gamma$-valerolactone over $\mathrm{ZrO}_{2}$ catalyst supported on SBA-15 silica. Catal. Today 2017, 281, 418-428. [CrossRef] 
9. Lomate, S.; Sultana, A.; Fujitani, T. Effect of $\mathrm{SiO}_{2}$ support properties on the performance of $\mathrm{Cu}-\mathrm{SiO} 2$ catalysts for the hydrogenation of levulinic acid to gamma valerolactone using formic acid as a hydrogen source. Catal. Sci. Technol. 2017, 7, 3073-3083. [CrossRef]

10. Lomate, S.; Sultana, A.; Fujitani, T. Vapor Phase Catalytic Transfer Hydrogenation (CTH) of Levulinic Acid to $\gamma$-Valerolactone Over Copper Supported Catalysts Using Formic Acid as Hydrogen Source. Catal. Lett. 2018, 148, 348-358. [CrossRef]

11. Kuwahara, Y.; Kango, H.; Yamashita, H. Catalytic Transfer Hydrogenation of Biomass-Derived Levulinic Acid and Its Esters to $\gamma$-Valerolactone over Sulfonic Acid-Functionalized UiO-66. ACS Sustain. Chem. Eng. 2017, 5, 1141-1152. [CrossRef]

12. Wijaya, Y.P.; Grossmann-Neuhaeusler, T.; Dhewangga Putra, R.D.; Smith, K.J.; Kim, C.S.; Gyenge, E.L. Electrocatalytic Hydrogenation of Guaiacol in Diverse Electrolytes Using a Stirred Slurry Reactor. ChemSusChem 2020, 13, 629-639. [CrossRef] [PubMed]

13. Xu, S.; Zhou, P.; Zhang, Z.; Yang, C.; Zhang, B.; Deng, K.; Bottle, S.; Zhu, H. Selective Oxidation of 5-Hydroxymethylfurfural to 2,5-Furandicarboxylic Acid Using $\mathrm{O}_{2}$ and a Photocatalyst of Co-thioporphyrazine Bonded to g- $\mathrm{C}_{3} \mathrm{~N}_{4}$. J. Am. Chem. Soc. 2017, 139, 14775-14782. [CrossRef] [PubMed]

14. Li, Z.; Garedew, M.; Lam, C.H.; Jackson, J.E.; Miller, D.J.; Saffron, C.M. Mild electrocatalytic hydrogenation and hydrodeoxygenation of bio-oil derived phenolic compounds using ruthenium supported on activated carbon cloth. Green Chem. 2012, 14, 2540-2549. [CrossRef]

15. Li, Z.; Kelkar, S.; Raycraft, L.; Garedew, M.; Jackson, J.E.; Miller, D.J.; Saffron, C.M. A mild approach for bio-oil stabilization and upgrading: Electrocatalytic hydrogenation using ruthenium supported on activated carbon cloth. Green Chem. 2014, 16, 844-852. [CrossRef]

16. Song, Y.; Gutiérrez, O.Y.; Herranz, J.; Lercher, J.A. Aqueous phase electrocatalysis and thermal catalysis for the hydrogenation of phenol at mild conditions. Appl. Catal. B 2016, 182, 236-246. [CrossRef]

17. Chadderdon, X.H.; Chadderdon, D.J.; Pfennig, T.; Shanks, B.H.; Li, W. Paired electrocatalytic hydrogenation and oxidation of 5-(hydroxymethyl)furfural for efficient production of biomass-derived monomers. Green Chem. 2019, 21, 6210-6219. [CrossRef]

18. Zhang, P.; Sheng, X.; Chen, X.; Fang, Z.; Jiang, J.; Wang, M.; Li, F.; Fan, L.; Ren, Y.; Zhang, B.; et al. Paired Electrocatalytic Oxygenation and Hydrogenation of Organic Substrates with Water as the Oxygen and Hydrogen Source. Angew. Chem. Int. Ed. 2019, 58, 9155-9159. [CrossRef]

19. Zhang, Y.R.; Wang, B.X.; Qin, L.; Li, Q.; Fan, Y.M. A non-noble bimetallic alloy in the highly selective electrochemical synthesis of the biofuel 2,5-dimethylfuran from 5-hydroxymethylfurfural. Green Chem. 2019, 21, 1108-1113. [CrossRef]

20. Zhang, X.; Han, M.; Liu, G.; Wang, G.; Zhang, Y.; Zhang, H.; Zhao, H. Simultaneously high-rate furfural hydrogenation and oxidation upgrading on nanostructured transition metal phosphides through electrocatalytic conversion at ambient conditions. Appl. Catal. B 2019, 244, 899-908. [CrossRef]

21. Nilges, P.; Dos Santos, T.R.; Harnisch, F.; Schröder, U. Electrochemistry for biofuel generation: Electrochemical conversion of levulinic acid to octane. Energy Environ. Sci. 2012, 5, 5231-5235. [CrossRef]

22. Dos Santos, T.R.; Nilges, P.; Sauter, W.; Harnisch, F.; Schröder, U. Electrochemistry for the generation of renewable chemicals: Electrochemical conversion of levulinic acid. RSC Adv. 2015, 5, 26634-26643. [CrossRef]

23. Xin, L.; Zhang, Z.; Qi, J.; Chadderdon, D.J.; Qiu, Y.; Warsko, K.M.; Li, W. Electricity Storage in Biofuels: Selective Electrocatalytic Reduction of Levulinic Acid to Valeric Acid or $\gamma$-Valerolactone. ChemSusChem 2013, 6, 674-686. [CrossRef] [PubMed]

24. Qiu, Y.; Xin, L.; Chadderdon, D.J.; Qi, J.; Liang, C.; Li, W. Integrated electrocatalytic processing of levulinic acid and formic acid to produce biofuel intermediate valeric acid. Green Chem. 2014, 16, 1305-1315. [CrossRef]

25. Wu, H.; Song, J.; Xie, C.; Hu, Y.; Zhang, P.; Yang, G.; Han, B. Surface engineering in PbS via partial oxidation: Towards an advanced electrocatalyst for reduction of levulinic acid to $\gamma$-valerolactone. Chem. Sci. 2019, 10, 1754-1759. [CrossRef]

26. Sanyal, U.; Lopez-Ruiz, J.; Padmaperuma, A.B.; Holladay, J.; Gutiérrez, O.Y. Electrocatalytic Hydrogenation of Oxygenated Compounds in Aqueous Phase. Org. Process Res. Dev. 2018, 22, 1590-1598. [CrossRef]

27. Zhao, B.; Chen, M.; Guo, Q.; Fu, Y. Electrocatalytic hydrogenation of furfural to furfuryl alcohol using platinum supported on activated carbon fibers. Electrochim. Acta 2014, 135, 139-146. [CrossRef] 
28. Jung, S.; Karaiskakis, A.N.; Biddinger, E.J. Enhanced activity for electrochemical hydrogenation and hydrogenolysis of furfural to biofuel using electrodeposited Cu catalysts. Catal. Today 2019, 323, $26-34$. [CrossRef]

29. Zhang, L.; Zhang, F.; Michel, F.C., Jr.; Co, A.C. Efficient Electrochemical Hydrogenation of 5-Hydroxymethylfurfural to 2,5-Bis(hydroxymethyl)furan on Ag-Displaced Nanotextured Cu Catalysts. ChemElectroChem 2019, 6, 4739-4749. [CrossRef]

30. Serrano-Ruiz, J.C.; Wang, D.; Dumesic, J.A. Catalytic upgrading of levulinic acid to 5-nonanone. Green Chem. 2010, 12, 574-577. [CrossRef]

31. Jung, S.; Biddinger, E.J. Electrocatalytic Hydrogenation and Hydrogenolysis of Furfural and the Impact of Homogeneous Side Reactions of Furanic Compounds in Acidic Electrolytes. ACS Sustain. Chem. Eng. 2016, 4, 6500-6508. [CrossRef]

32. Bisselink, R.J.M.; Crockatt, M.; Zijlstra, M.; Bakker, I.J.; Goetheer, E.; Slaghek, T.M.; van Es, D.S. Identification of More Benign Cathode Materials for the Electrochemical Reduction of Levulinic Acid to Valeric Acid. ChemElectroChem 2019, 6, 3285-3290. [CrossRef]

33. Holzhäuser, F.J.; Artz, J.; Palkovits, S.; Kreyenschulte, D.; Büchs, J.; Palkovits, R. Electrocatalytic upgrading of itaconic acid to methylsuccinic acid using fermentation broth as a substrate solution. Green Chem. 2017, 19, 2390-2397. [CrossRef]

(C) 2020 by the authors. Licensee MDPI, Basel, Switzerland. This article is an open access article distributed under the terms and conditions of the Creative Commons Attribution (CC BY) license (http://creativecommons.org/licenses/by/4.0/). 